\title{
POSTURAL BALANCE AND ANTI-GRAVITATION \\ MUSCLE STRENGTH IN WOMEN WHO DO INDONESIA HEALTHY GYMNASTICS
}

\author{
Sumanto \\ School of Health Polytechnics, Ministry of Health, Surakarta
}

\begin{abstract}
Background: Balance is the ability to maintain the center of gravity over the base of support, usually while in an upright position. Balance is a complex function involving numerous neuromuscular processes. The factors having direct influence on the ability to maintain the balancing position may be sensory information, coordination, range of joint movements and muscle strength. Muscle strength is an important aspect of physical fitness and health status, and a decrease of muscle strength may cause significant functional limitations. This study aimed to test the effect on postural balance and anti-gravitation muscle strength in women who do Indonesian healthy tera gymnastics.
\end{abstract}

Subjects and Method: This was a randomized controlled trial carried out in Surakarta. A total of 160 people 55 to 65 years of age were selected for this study and divided into two groups: (1) Tera gymnastics group; (2) Control group. The dependent variables were postural balance and anti-gravitation muscle strength. The independent variable was Indonesian healthy tera gymnastics. Data on postural balance was measured by posturometer, and anti-gravitation muscle strength was measured by dynamometer. The scores between two groups were tested by ttest.

Results: Wobble frequency was lower in the gymnastics group than in the control group, and it was statistically significant. Wobble amplitude was lower in the gymnastics group than in the control group, and it was statistically significant.

Conclusion: Tera healthy gymnastics is effective to improve postural balance as indicated by low wobble frequency and amplitude.

Keywords: healthy gymnastics, postural balance, wobble frequency, amplitude.

\section{Correspondence:}

Sumanto. School of Health Polytechnics, Ministry of Health, Surakarta, Central Java. Email: sumantoiman@gmail.com. Mobile: 08121508067.

The 4th International Conference on Public Health Best Western Premier Hotel, Solo, Indonesia, August 29-30, 2018 | 307 https://doi.org/10.26911/theicph.2018.05.21 